\title{
Recorregut de recerca geològica mineralògica i patrimonial pel Principat d'Andorra: des de La Massana a Ordino i a Llors. Ruta del ferro d'Andorra
}

Josep Maria Mata-Perelló

Joaquim Sanz Balagué
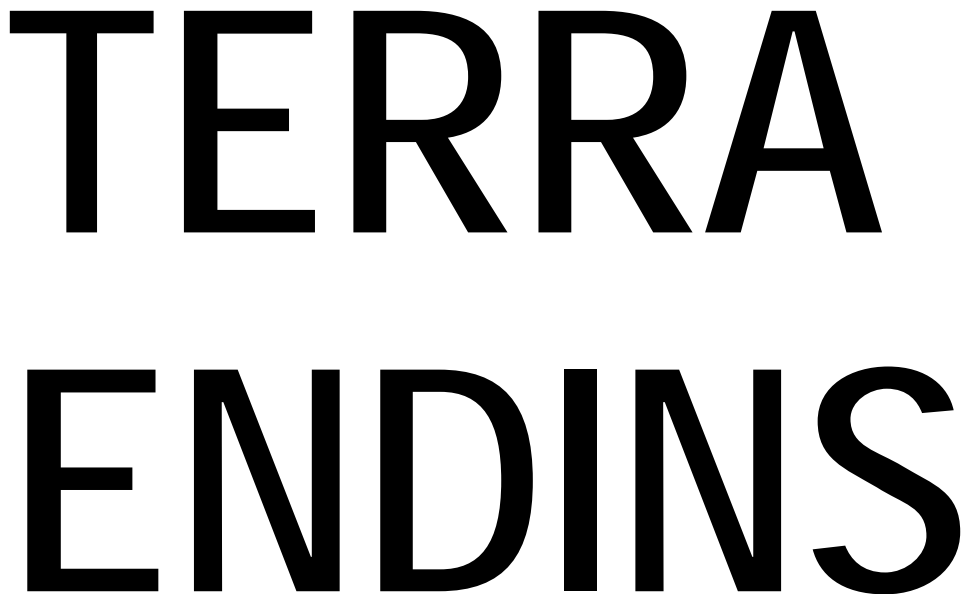

\section{REVISTA DE GEOLOGIA}

n. 4

DESEMBRE 2015 


\section{RECORREGUT DE RECERCA GEOLÒGICA MINERALÒGICA I PATRIMONIAL PEL PRINCIPAT D'ANDORRA: DES DE LA MASSANA A ORDINO I A LLORS. RUTA DEL FERRO D'ANDORRA}

\section{Josep Maria Mata-Perelló}

Museu de geologia Valentí Masachs, Escola Politècnica Superior d'Enginyeria de Manresa (EPSEM), Universitat Politècnica de Catalunya · BarcelonaTech (UPC), 08272 Manresa, Spain

\section{Joaquim Sanz Balagué}

Departament d'Enginyeria Minera i Recursos Naturals (EMRN), Escola Politècnica Superior d'Enginyeria de Manresa (EPSEM), Universitat Politècnica de Catalunya - BarcelonaTech (UPC), 08272 Manresa, Spain

Paraules clau: Patrimoni geològic i miner; ferro; Andorra

\section{Resum}

Recorregut realitzat el dia 14 de juliol del 2014. En aquesta ocasió, el recorregut de l'itinerari discorrerà serà una mica atípic, ja que es tractarà fonament de veure el Patrimoni Miner $\mathrm{i}$ Metal•lúrgic relacionat amb la mineria del ferro al Principat d'Andorra.

Aquest recorregut, per altra banda, es desenvoluparà íntegrament pels Apilaments Antiformes de la Zona Axial Pirinenca. Així, al llarg del recorregut anirem trobant afloraments dels materials paleozoics, fonamentalment del Cambro - Ordovicià, de I'Ordovicià i del Silurià. Aquests materials seran fonamentalment pissarres i esquistos.

També, trobarem per arreu abundants depòsits neògens dels Pleistocè i de l'Holocè (del també denominat Quaternari). Aquests depòsits seran fonamentalment d'origen glacial (les conegudes morrenes) o fluvial (les terrasses). Igualment veurem abundants depòsits col•luvials, de despreniments.

Per d'altra banda, en aquest recorregut veurem els evidents riscos generats en fer les construccions sense tenir en comte (o prou en compte) la geologia de la zona.

Aquest recorregut, es realitzarà totalment per les Valls d'Andorra, entre La Massana, Ordino i Llorts, passant també per les poblacions de: Sornas, Ansalonga, la Cortinada i Arans. El final del recorregut serà a la Mina de Ferro de Llorts 


\section{ADVERTIMENT PREVI}

Com en altres recorreguts de RECERCA GEOLÒGICA I MINERALÒGICA ..., si es disposa del temps suficient, poden efectuar-se passant per totes les parades i filloles. En cas contrari, recomanem prescindir de les anomenades PARADES - CONDICIONALS.

També recomanem que es demani informació sobre l'estat dels diferents trams de les pistes forestals, per les quals s'ha de circular, en el recorregut de l'itinerari, per tal d'evitar problemes secundàries.

Per d'altra banda, i a l'igual que en altres recorreguts semblants, recomanem tenir el màxim de cura i de respecte, entorn de la Natura que ens rodeja.

\section{OBJECTIUS GENERALS}

Es centraran en els aspectes geològics, geomorfològics i mineralògics que apuntarem a continuació:

1.- Observació de l'estructura dels Apilaments Antiformes de la Zona Axial Pirinenca, per entre la qual discorrerà el recorregut de l'itinerari, que anirem trobant a diferents indrets del recorregut. Fonamentalment, aquests afloraments correspondran a l'Ordovicià amb nivells d'esquistos, calcosquistos i de quarsites) i al Silurià (amb pissarres negres). Tanmateix també trobarem afloraments de granits del Carbonífer.

2.- Observació dels materials neògens (del Pleistocè i de l’Holocè, també dits del Quaternari), que corresponen als depòsits morrènics, fluvial i col-luvials. Els anirem trobant a diferents indrets de les Valls d'Andorra.

3.- Reconeixement de diverses mineralitzacions situades al llarg del recorregut, com les mineralitzacions ferruginoses associades a rebliments Kàrstic (que no veurem, però que han estat la principal matèria prima d'obtenció de mineres de ferro) o les mineralitzacions ferruginoses d'alteració de sulfurs de ferro, que veurem a Llorts.

4.- Reconeixement de les explotacions mineres, antigues i actuals, relacionades amb les mineralitzacions esmentades a l'apartat anterior.

5.- Observació dels impactes produïts per les explotacions anteriors, sobre el Medi Natural i sobre el Medi Ambient.

5.- Observació, al llarg del recorregut, dels diferents indrets relacionats amb el Patrimoni Geològic i amb el Patrimoni Miner

6.- Observació, de les zones de risc, produïdes pel creixement urbanístic dintre de nombrosos llocs de les Valls d’Andorra. 


\section{ANTECEDENTS}

En relació a aquest recorregut, nosaltres no tenim cap antecedent nostre; així que per nosaltres és una primícia. Hi ha un antecedent a la Ruta Minera del Ferro (http://www.ordino.ad/estiu/descobreix/ruta_ferro.aspx).

Pel que toca al coneixement de les estructures geològiques que veurem en aquest itinerari hi ha l'antecedent local de BERASTEGUI et altri (1993); aquest antecedent es relatiu a un treball de l'IGME, relatiu a l'àrea recorreguda.

Altres antecedents, de caràcter estructurals, i relatius al conjunt dels Països Catalans, són els següents: RIBA et altri (1976) i GUIMERÀ (1982); així com SGC (1990). Altres antecedents, de caràcter estructurals, i relatius al conjunt dels Països Catalans, són els següents: RIBA et altri (1976) i GUIMERÀ (1982); així com SGC (1990).

Finalment, i pel que fa a les mineralitzacions que trobarem al llarg del recorregut, ens referirem a: MATA-PERELLÓ (1994), en un estudi relatiu al conjunt de les mineralitzacions andorranes..

Evidentment, totes aquestes referències bibliogràfiques, figuraran degudament relacionades, per ordre alfabètic, dintre de l'apartat dedicat a les REFERÈNCIES BIBLIOGRÀFIQUES.

\section{DESCRIPCIÓ DEL RECORREGUT DE L’ITINERARI}

El recorregut d'aquest itinerari es desenvoluparà íntegrament pel Principat d'Andorra, per les Valls d'Andorra. Així, el recorregut s'iniciarà a La Massana, prop d'on es farà la primera aturada, a la coneguda Farga Rossell.

Després el recorregut continuarà per la carretera general andorrana CG - 3, anant cap al poble d'Ordino, per on es farà una altra aturada. Tot seguit continuarà cap al Nord, passant pels pobles de: Sornas, Ansalonga, la Cortinada i Arans. Finalment, s'arribarà a Llorts, per on es farà la darrera aturada a final a la Mina de Ferro de Llorts

\section{DESCRIPCIÓ DE L’ITINERARI}

En aquest recorregut hem situat, com ja és habitual en tots els itineraris, una sèrie 
d'ESTACIONS o de PARADES, que anirem veient a continuació. En cada cas, els hi donarem una denominació que podrà correspondre a algun paratge proper. També indicarem el terme municipal i la comarca on es troba.

Per d'altra banda, en cadascuna de les parades, indicarem entre parèntesi el número del mapa topogràfic, a escala 1:50.000, on es troba situada la parada considerada. En aquesta ocasió utilitzarem una doble nomenclatura: per una banda, si s’escau, utilitzarem un sol full de la CME ("Cartografia Militar de España"): concretament el 183 (o d'Andorra)..

Així, passarem a continuació, a fer una referència ordenada, de les diferents aturades que composen el recorregut del present itinerari.

PARADA 1. FARGA ROSSELL, (terme de la parròquia de la Massana, Principat d'Andorra). (Full 183).

En aquest indret hi ha una antiga farga catalana reconstruïda i habilitada per ésser visitada, per al denominat turisme científic. Així a la Farga Rossell, completament restaurada i convertida en Centre d’Interpretació del Ferro, ens mostra mitjançant un audiovisual com es produeix el procés de transformació del mineral de ferro en lingots $\mathrm{i}$ la importància de la metal-lúrgia a Andorra a finals del segle XIX i principis del XX. En aquesta musealització, també es pot veure el funcionament del martinet propulsat per aigua. Al mateix temps es pot veure com s'obtenien els lingots.

La restauració ha estat molt ben realitzada i permet conèixer de prop una de les fargues més actives dels Pirineus durant els passats segles. FOTOGRAFIES 1 i 2.

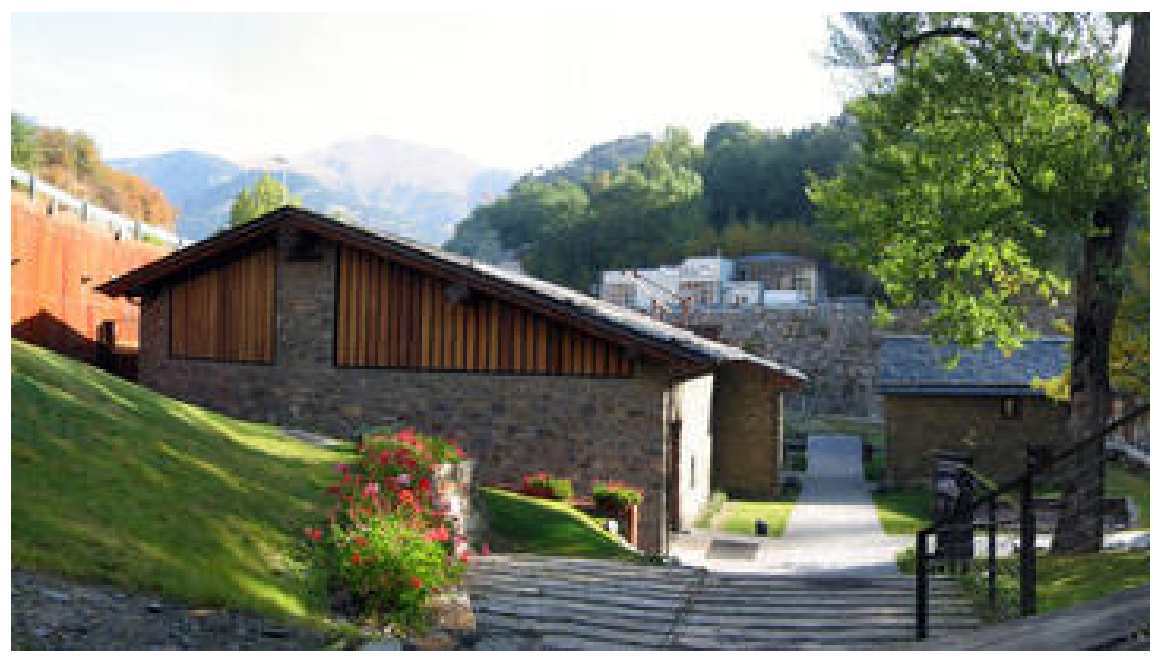

FOTOGRAFIA 1. PARADA 1

Un aspecte de la Farga Rossell. https://www.google.es/search?q=FARGA+ROSSELL, + ANDORRA 


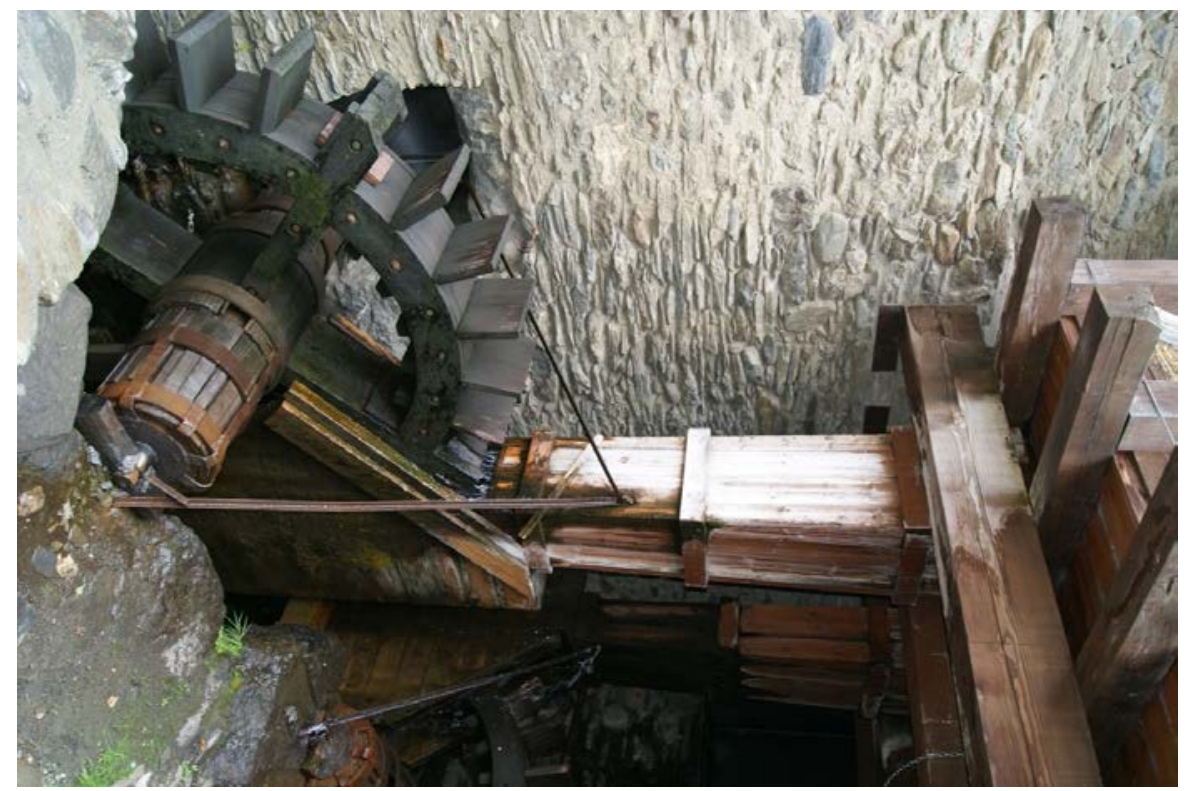

FOTOGRAFIA 2. PARADA 1

El Martinet de la Farga Rossell.

https://www.google.es/search?q=FARGA+ROSSELL,+ANDORRA

Per d'altra banda, cal dir que aquí s'utilitzaven els minerals de ferro trets de les mines anomenades Els Meners. Aquestes estaven situades a l paratge de la Coma de Ransol. Es tracta de mineralitzacions estratiformes associades a nivells carbonatats. Els minerals més abundants són; HEMATITES, GOETHITA (limonita) i SIDERITA

\section{PARADA 2 - CONDICIONAL. SORTIDA D'ORDINO CAP A LLORTS, (terme de la Parròquia d'Ordino, Principat d'Andorra). (Full 183).}

Després de fer l'aturada anterior, cal sortir de la Massana per la carretera CG - 3, per tal d'anar cap a la propera població d'Ordino. Després de travessar la població, si s'escau, es pot fer una aturada a la bora de la carretera, anant ara cap a Llorts. Així, des de la parada anterior, haurem recorregut uns 2’5 Km, per tal d'arribar fins aquí.

En aquest recorregut, ens hem estat movent sempre dintre dels Apilaments Antiformes de la Zona Axial Pirinenca. Així, per tot arreu s'han fet palesos els afloraments dels esquistos i quarsites de l'Ordovicià Efectivament, a l'indret on ara som, es fan palesos els afloraments d'aquests materials, just a la bora del riu de la Valira del Nord.

\section{PARADA 3. ESGLÈSIA PARROQUIAL DE LA CORTINADA, (la}


Cortinada, terme de la Parròquia d'Ordino, Principat d'Andorra). (Full 183).

Després de fer l'anterior aturada, ens caldrà continuar cap el Nord, utilitzant la carretera CG - 3. Per aquesta passarem per Sornas i Ansalonga. Després arribarem a la Cortinada, per on farem una nova aturada. Aquesta la farem prop de l'Església Parroquial. Així, des de la parada anterior, haurem efectuat un recorregut proper als $3 \mathrm{Km}$.

En aquest recorregut, no han variat les característiques geològiques. En efecte, ens hem estat desplaçant dintre dels Apilaments Antiformes de la Zona Axial Pirinenca. Així, fonamentalment, hem trobat afloraments dels materials de l'Ordovicià. Aquests són també els materials que apareixem entorn al poble.

En aquest indret, es poden veure alguns dels forjats fet a partir dels minerals de ferro, extrets a la vall i processats a les fargues.

PARADA 4. MINA DE FERRO DE LLORTS, (Llorts, terme de la Parròquia d'Ordino, Principat d'Andorra). (Full 183).

Després de fer l'aturada anterior, sols cal continuar cap el Nord, utilitzant la carretera CG - 3. Així, primer es passarà per Arans i finalment s'arribarà a Llorts, En arribar a aquest indret, caldrà anar cap a les Mines de Ferro de Llorts, per on farem la propera aturada. Així, haurem recorregut uns $3 \mathrm{Km}$, més.

Com als recorreguts anteriors, en aquest hem anat trobant afloraments dels materials paleozoics de l'Ordovicià i ocasionalment del Silurià. Aquests materials es situen dintre dels Apilaments Antiformes de la Zona Axial Pirinenca, , per on estem ara situats i hem estat situats al llarg de tot aquest recorregut.

En aquest indret, s'ha recuperat una antiga mineta de ferro. En aquesta s'aprofitaven unes mineralitzacions d'oxidació de sulfurs. Efectivament, per l'alteració de sulfurs de ferro situats entre els afloraments paleozoics, s'han originat òxids de ferro, com GOETHITA, LEPIDOCROCITA, TURGITA i HEMATITES. Al mateix temps s'han originat diferents sulfats de ferro, com la MELANTERITA.

Pel que fa a la mina recuperada, tot i la seva escassa longitud, cal dir que es un element força interessant de cara a l'aprofitament del turisme científic. FOTOGRAFIA 3. 


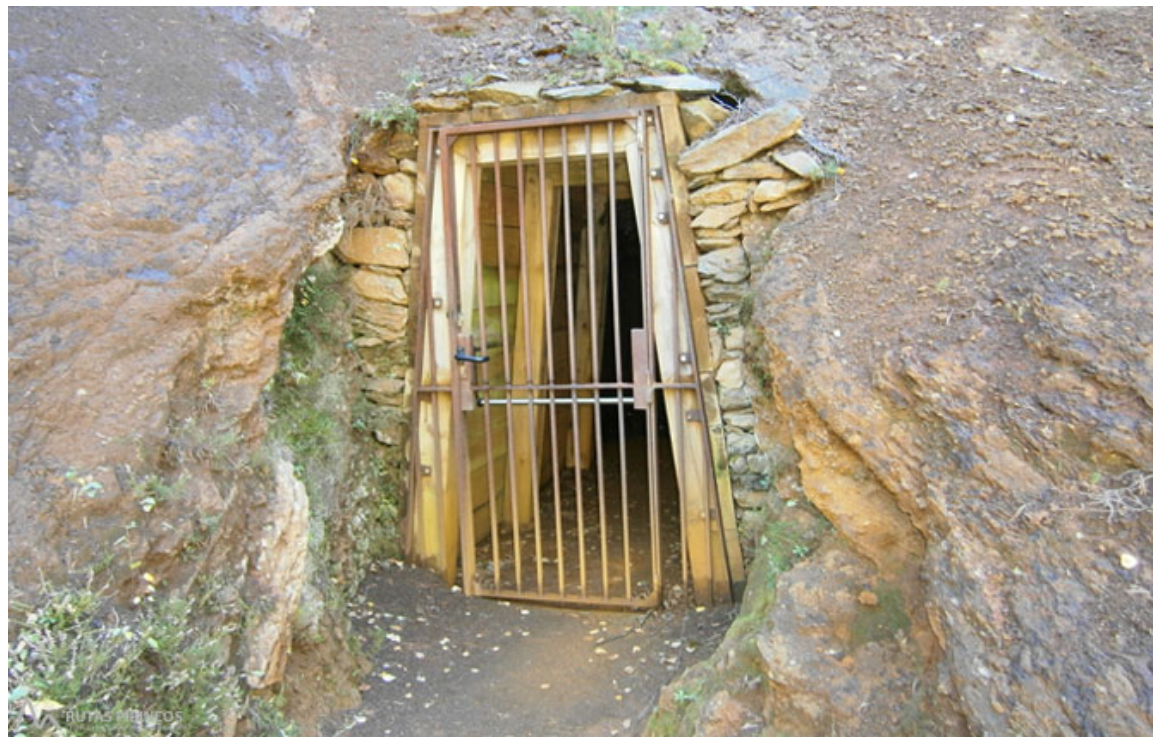

FOTOGRAFIA 3. PARADA 4

Entrada a la Mina de Ferro de Llorts

\section{EN AQUEST INDRET FINALITZA EL RECORREGUT}

\section{BIBLIOGRAFIA EMPRADA}

BERASTEGUI, X. et altri ( 1993).- Tall geològic del Pirineu central. Servei Geològic de Catalunya, Institut Cartogràfic de Catalunya. Col·lecció 1:200.000. Barcelona

GUIMERÀ, J. et altri (1992).- Geologia (II), Història Natural dels Països Catalans, Vol. 2, 547 pag. Enciclopèdia Catalana, S.A. Barcelona

MATA - PERELLÓ, J. M., (1994).- Els Minerals d’Andorra. Col·lecció Xaragall, $\mathrm{n}^{0}$ 3, 34 pàgines. Manresa

RIBA ARDERIU, O. Et altri. (1976).- Geografia Fisica dels Països Catalans. Edit Ketres, 254 pàgines. Barcelona

SGC (1990).- Mapa Geològic de Catalunya a escala 1:250.000, Servei Geològic de Catalunya (Inst. Cartògraf . de Catalunya). Barcelona 